\title{
Subdural to subgaleal shunts: alternative treatment in infants with nonaccidental traumatic brain injury?
}

\author{
Thomas Blauwblomme, MD,,,2 Federico Di Rocco, MD, PhD,, Marie Bourgeois, MD,, ${ }^{1,2}$ \\ Kevin Beccaria, MD, ${ }^{1,2}$ Giovanna Paternoster, MD, ${ }^{1}$ Juliette Verchere-Montmayeur, MD, ${ }^{3}$ \\ Christian Sainte-Rose, MD, ${ }^{1,2}$ Michel Zerah, MD, ${ }^{1,2}$ and Stéphanie Puget, MD, PhD ${ }^{1,2}$
} Departments of ${ }^{1}$ Pediatric Neurosurgery and ${ }^{3}$ Anesthesiology, Hôpital Necker Enfants Malades; and ${ }^{2}$ Université Paris Descartes,
Sorbonne Paris Cité, Paris, France

OBJECT The ideal treatment for subdural hematomas (SDHs) in infants remains debated. The aim of this study was to analyze the safety and efficiency of subduro-subgaleal drainage in SDH.

METHODS The authors conducted a single-center open-label study between August 2011 and May 2012. Data were prospectively collected in a database and retrospectively analyzed.

RESULTS Eighteen patients (male/female ratio 1.25) with a median age of 5 months were surgically treated. All had preoperative symptoms of intracranial hypertension or seizures. The SDH was bilateral in 16 cases, with a median width of $12 \mathrm{~mm}$. Success of the procedure was noted in 14 of the 18 patients. There was no intraoperative complication or postoperative infection. Drainage failure was attributable to suboptimal positioning of the subdural drain in 2 cases and to migration in 1 case.

CONCLUSIONS Subduro-subgaleal drainage is an efficient treatment that could be proposed as an alternative to external subdural drainage or subduroperitoneal drainage.

http://thejns.org/doi/abs/10.3171/2014.9.PEDS1485

KEY WORDS subdural hematomas; nonaccidental traumatic brain injury; subduroperitoneal shunts; subgaleal shunts; hydrocephalus; trauma

A LTHOUGH the optimal treatment of chronic subdural hematomas (SDHs) has been identified for the elderly through randomized prospective studies, the ideal surgical treatment for infants remains debated. ${ }^{12}$ Different studies propose the use of transfontanellar puncture, external drainage, subduroperitoneal (SDP) drainage, or even craniotomy. ${ }^{5,8,9,14,16,17}$ Each technique has drawbacks - infection, catheter obstruction, or invasiveness in opposition to its efficiency.

During the past decades, ventriculo-subgaleal drainage in preterm infants has proved to be an efficient, yet transient, technique for posthemorrhagic hydrocephalus. ${ }^{6}$ It was shown to decrease the risk of secondary shunt dysfunction by clearance of the CSF, with a low infection rate. ${ }^{15}$ Moreover, it does not require peritoneal access. Al- ternative uses for the subgaleal shunt have been proposed in cases of trauma, hygroma, or meningitis. ${ }^{7,10,13,15}$

We postulated that subgaleal drainage could also be used to treat SDH in infants; therefore, we conducted a single-center open-label study to investigate its safety and efficiency.

\section{Methods}

\section{Study Design, Setting, and Participants}

We performed an uncontrolled single-center open-label trial from August 2011 to May 2012 in the neurosurgical department of Necker Hospital, Paris, France. All infants with nonaccidental traumatic brain injury who were referred to our department for surgical treatment were in- 
cluded in our present analysis. The decision to operate was made if patients were symptomatic (intracranial hypertension or seizure). During the postoperative period, infants were kept horizontal as much as possible. Parents were asked to call the hospital if the subgaleal pocket collapsed.

\section{Variables, Data Source, and Measurements}

Data had been prospectively recorded in a dedicated database. We collected information on preoperative clinical symptoms (intracranial hypertension, seizures, neurological deficit, retinal hemorrhage) and radiological features (CT density, maximal width of the SDH, midline shift). The following surgical data were recorded: length and side of catheter, gross aspect of SDH, duration of surgery, and intra- or postoperative complication. We assessed on serial postoperative imaging the correct localization of the drain and the width of the subdural collection. Success of the procedure was defined as complete disappearance of the subdural collection on the last imaging session. The failure of surgery was characterized as a collapse of the subgaleal space with persistence of the SDH on CT and/or MRI. The time to recovery was calculated as the interval between surgery and the last imaging follow-up.

\section{Study Size}

We stopped the study after enrolling 18 patients to analyze our results after we experienced 2 consecutive drainage failures.

\section{Quantitative Variables and Statistical Methods}

We used IBM SPSS Statistics 20 for Mac to perform our statistical analysis. Quantitative variables were analyzed with a nonparametric Kruskal-Wallis test, and qualitative variables were analyzed using the Fisher exact test. The level of significance was set at 0.05 . We did not take into account the duration of hospitalization after surgery because it was not related to the medical data but was instead more related to the legal aspects of managing these nonaccidental traumatic brain injuries.

\section{Results \\ Descriptive Data \\ Patients}

Eighteen infants were surgically treated in this study, and none were lost to follow-up (Table 1). There were 10 boys and 8 girls (male/female ratio 1.25). The median age at surgery was 5 months (range 1-9 months). Preoperative symptoms were as follows: intracranial hypertension (14 patients), seizures (7 patients), and retinal hemorrhage (11 patients). The median head circumference was $44 \mathrm{~cm}$ (range 40-51 cm, $+2.5 \mathrm{SD}$ below the mean). None of the patients had clotting disorders, nor was there any history of direct head trauma.

Preoperative imaging included a head CT scan in every case and an MR image in 14 cases. The hematoma was bilateral in 16 cases and unilateral in 2 cases. It was hypodense in 8 cases (chronic SDH), hyperdense in 1 case (acute SDH), and iso-hyperdense in 9 cases (subacute SDH). Maximal hematoma width ranged between 8 and $25 \mathrm{~mm}$ (median $12 \mathrm{~mm}$ ).

\section{Surgical Procedure}

The drainage was unilateral. A 3-cm curvilinear incision was made above the external angle of the anterior fontanel. Wide subgaleal dissection $8-10 \mathrm{~cm}$ in diameter was done above the calvaria. A 3-cm catheter was inserted in the subdural space through the fontanel and connected to a multiperforated $15-\mathrm{cm}$ distal catheter located in the subgaleal space (Fig. 1). The system was fixed to the fontanel with a nonabsorbable suture.

We inserted the drain on the side of the largest SDH in the case of bilateral hematomas. The drain was inserted on the right side in 12 of 18 cases, and the median operative time was 20 minutes (range 10-30 minutes).

The SDH was under high pressure in 15 cases. Its aspect was xanthochromic in 13 cases and reddish in 3 cases (not reported in 2 cases).

\section{Outcome Data}

There was no intraoperative complication or any infection. The median duration of hospitalization after surgery was 7 days (range 3-25 days) but was related to social and legal issues. Drainage success was noted in 14 of 18 cases. The median delay between surgery and the first MRI study that showed disappearance of the SDH was 69 days (range 28-253 days).

In cases of success, ablation of the subdural drain was performed. This was done during a 2-day hospitalization and required a short period of general anesthesia. No complication was related to the ablation.

Failure of the subgaleal drainage was noted in 4 cases (Table 1). Second-line surgical treatment to place an SDP shunt was performed in each of these cases and was successful. None of the patients had signs of relapse of the intracranial hypertension or seizure. In 1 case, there was outward migration of the subdural catheter in the subgaleal space 22 days after treatment. In 3 cases, dysfunction of the subdural shunt was noted. In 1 of these cases, rebleeding occurred and led to obstruction, which was diagnosed on imaging 28 days after the first surgery. In 2 of the cases, placement of the subdural catheter was suboptimal, and dysfunction was seen on imaging 47 and 89 days after the first surgery, respectively.

\section{Other Analyses}

We did not find a significant difference between the patients who were successfully treated with a subgaleal shunt and those who were not. Head circumference and maximal hematoma width were not different $(\mathrm{p}=0.16$ and 0.232, respectively; Kruskal-Wallis test). Age at surgery and delay between symptoms and surgical treatment were similar as well ( $\mathrm{p}=0.362$ and 0.262 , respectively; Kruskal-Wallis test). Hematoma density or location (unior bilateral) was not different ( $\mathrm{p}=0.844$ and 0.929 , respectively; Pearson chi-square test).

\section{Discussion}

The treatment of SDH in infants remains debated, with 4 possible treatments. Repeated subdural taps have often been shown to be inefficient, with as many as $42 \%$ of the patients requiring further treatments and a high rate of in- 
TABLE 1. Summary of characteristics in 18 patients who underwent placement of a subduro-subgaleal shunt

\begin{tabular}{cllcl}
\hline $\begin{array}{c}\text { Case No./Sex/Age } \\
\text { at Surgery (mos) }\end{array}$ & Preop Symptoms & $\begin{array}{c}\text { Imaging Results: Hematoma } \\
\text { Side/Density/Width }(\mathrm{mm})\end{array}$ & $\begin{array}{c}\text { Delay Btwn Surgery \& } \\
\text { Last Imaging (days) }\end{array}$ & Success \\
\hline $1 / \mathrm{F} / 4$ & $\mathrm{Sz} / \mathrm{RH}$ & Bilat/isodense/11 & 30 & Yes \\
\hline $2 / \mathrm{M} / 4$ & $\mathrm{ICHT} / \mathrm{RH}$ & Bilat/hypodense/13 & 89 & Yes \\
\hline $3 / \mathrm{M} / 1$ & $\mathrm{ICHT}$ & Bilat/hypodense/25 & 95 & Yes \\
\hline $4 / \mathrm{F} / 5$ & $\mathrm{ICHT} / \mathrm{RH}$ & Bilat/mixed/10 & 37 & Yes \\
\hline $5 / \mathrm{F} / 7$ & $\mathrm{ICHT/Sz/RH}$ & Bilat/mixed/10 & 158 & Yes \\
\hline $6 / \mathrm{F} / 2$ & $\mathrm{Sz} / \mathrm{RH}$ & Bilat/mixed/10 & 50 & Yes \\
\hline $7 / \mathrm{M} / 3$ & $\mathrm{ICHT} / \mathrm{RH}$ & Bilat/hypodense/8 & 31 & Yes \\
\hline $8 / \mathrm{M} / 8$ & $\mathrm{ICHT} / \mathrm{RH}$ & Unilat (rt)/hypodense/8 & 253 & Yes \\
\hline $9 / \mathrm{M} / 5$ & $\mathrm{ICHT}$ & Bilat/hypodense/9 & 86 & Yes \\
\hline $10 / \mathrm{F} / 2$ & $\mathrm{ICHT}$ & Bilat/mixed/13 & 180 & Yes \\
\hline $11 / \mathrm{F} / 5$ & $\mathrm{Sz} / \mathrm{RH}$ & Bilat/hypodense/13 & 55 & Yes \\
\hline $12 / \mathrm{M} / 9$ & $\mathrm{ICHT} / \mathrm{Sz} / \mathrm{RH}$ & Unilat (It)/mixed/12 & 83 & Yes \\
\hline $13 / \mathrm{M} / 3$ & $\mathrm{Sz}$ & Bilat/mixed/14 & 95 & Yes \\
\hline $14 / \mathrm{M} / 3$ & $\mathrm{ICHT} / \mathrm{Sz}$ & Bilat/hypodense/12 & 89 & No/suboptimal placement \\
\hline $15 / \mathrm{F} / 7$ & $\mathrm{ICHT} / \mathrm{RH}$ & Bilat/mixed/10 & 28 & Yes \\
\hline $16 / \mathrm{M} / 6$ & $\mathrm{ICHT}$ & Bilat/hypodense/20 & 28 & No/rebleeding \\
\hline $17 / \mathrm{M} / 5$ & $\mathrm{ICHT/RH}$ & Bilat/mixed/15 & 24 & No/suboptimal placement \\
\hline $18 / \mathrm{M} / 7$ & $\mathrm{ICHT}$ & Bilat/mixed/12 & 20 & No/migration \\
\hline
\end{tabular}

$\mathrm{ICHT}=$ intracranial hypertension; $\mathrm{RH}=$ retinal hemorrhage; $\mathrm{Sz}=$ seizure.

fectious complications (25\% of cases).$^{14}$ External drainage has been reported to be effective, with a success rate of $60 \%-95 \%{ }^{2,8,16}$ Nevertheless, drainage must be maintained for a long period (median 6-15 days), with hospitalization in the intensive care unit and hydro-electrolytic compensation; therefore, the economic cost is high and must be taken into account along with the actual economic context. Some authors still advocate the use of minicraniotomy given its good success rate, but this method is quite invasive. ${ }^{3}$

Subduroperitoneal drainage has been the gold standard in our department for more than 15 years, and other studies have shown excellent results for this procedure, with more than $90 \%$ success. ${ }^{4,5,9,17}$ The main advantages are a short period of hospitalization with continuous drainage and a low infection rate. Associated peritoneal complications are rare with 1 case of bowel perforation and 1 case of anal protrusion of the distal catheter in a series of 244
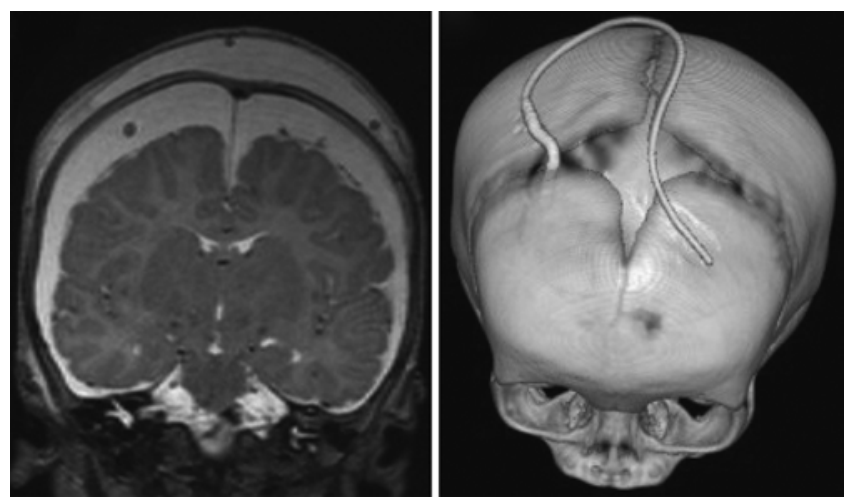

FIG. 1. Representative postoperative imaging. Left: Coronal T2-weighted MR image. Note the subdural catheter in the subdural space and the wide subgaleal pocket. Right: Three-dimensional CT scan. cases. ${ }^{17}$ Nevertheless, obstruction of the proximal catheter leading to insufficient drainage has been reported in $9 \%$ $17 \%$ of the cases in 3 large series. ${ }^{5,9,17}$ It required a second surgery in $10 \%$ of the entire cohort to treat residual subdural collections. When looking for a factor predictive of complications in SDP drainage, Kurschel et al. used multivariate analysis to demonstrate that spontaneous hyperdensity on pre- or postoperative CT was correlated with obstruction of the proximal catheter. ${ }^{5}$

During the last few decades, studies have shown that neonatal posthemorrhagic hydrocephalus can be successfully managed with ventriculo-subgaleal drainage., ${ }^{1,6,11}$ This transient drainage permits clearance of the CSF from blood, and therefore decreases the risk of secondary obstruction if a ventriculoperitoneal shunt is required.

Subgaleal drainage has also been reported for other indications, in particular, in acute head trauma or chronic subdural collections in 2 series with 26 and 22 patients. ${ }^{10,13}$ More recently, another team proposed subgaleal drainage for the treatment of acute subdural hemorrhage in 8 infants. These authors successfully infused streptokinase into the subdural space over 3 days, followed by drainage of the subdural collection in the subgaleal space.

In the present study, 14 (78\%) of 18 infants with an SDH were treated successfully with subduro-subgaleal drainage. There was no intraoperative complication or infection related to the procedure. Drainage was efficient in hypo- and hyperdense collections on CT, and even large hematomas ( $25 \mathrm{~mm}$ wide) could be treated. We reported 4 cases of failure, but in 3 cases, failure was directly related to surgical errors.

A source of bias in our study is the postoperative imaging follow-up, which was not scheduled on specific dates, and so the time to recovery was not precisely assessed. 
An advantage of our procedure, as compared with SDP drainage, is mainly its surgical simplicity, as it does not require peritoneal access. Advantages of subgaleal drainage, as compared with external drainage, are a low infection rate and short hospitalization after surgery.

The main disadvantage of our technique is the need for children to lie horizontally as much as possible during the postoperative period. Indeed, we noticed that drainage was more efficient with horizontal posturing of the children. This could interfere with the rehabilitation of these children, who need physiotherapy.

This pilot study has shown that subgaleal drainage is safe and efficient. One possible indication could be a contraindication to insert the drain in the peritoneum. As the main risk factor for obstruction of an SDP shunt is hyperdensity of the SDH on CT, we propose subgaleal drainage as an alternative treatment option in this case. On the other hand, we think that in the case of a hypodense hematoma, SDP drainage should be preferred because it has low morbidity and high efficiency and does not require any horizontal posturing of the children during the postoperative period.

\section{Conclusions}

Subdural to subgaleal space drainage is a safe and efficient procedure. It could be proposed as an alternative to external drainage or SDP shunts in cases of hyperdense SDH in infants with signs of intracranial hypertension.

\section{Acknowledgments}

We dedicate this work to Professor Dominique Rénier.

We thank the medical, paramedical, and social team in charge of infants with a subdural hematoma in our department: Mireille Amona, Christelle Custos, Aurelia Diaz, Katia Lind, Caroline Mignot, Claudine Maurey-Forquy, Marie-Hélène Muzy, and MarieClaire Caména d'Almeida.

\section{References}

1. Fulmer BB, Grabb PA, Oakes WJ, Mapstone TB: Neonatal ventriculosubgaleal shunts. Neurosurgery 47:80-84, 2000

2. Gaskill SJ, Oakes WJ, Marlin AE: Continuous external drainage in the treatment of subdural hematomas of infancy. Pediatr Neurosurg 17:121-123, 1991-1992

3. Klimo P Jr, Matthews A, Lew SM, Zwienenberg-Lee M, Kaufman BA: Minicraniotomy versus bur holes for evacuation of chronic subdural collections in infants-a preliminary single-institution experience. J Neurosurg Pediatr 8:423429, 2011

4. Korinth MC, Lippitz B, Mayfrank L, Gilsbach JM: Subduralatrial and subdural-peritoneal shunting in infants with chronic subdural fluid collections. J Pediatr Surg 35:1339-1343, 2000

5. Kurschel S, Puget S, Bourgeois M, Zerah M, Ofner P, Renier D: Factors influencing the complication rate of subduroperi- toneal shunt placement for the treatment of subdural hematomas in infants. J Neurosurg 106 (3 Suppl):172-178, 2007

6. Lam HP, Heilman CB: Ventricular access device versus ventriculosubgaleal shunt in post hemorrhagic hydrocephalus associated with prematurity. J Matern Fetal Neonatal Med 22:1097-1101, 2009

7. Larionov SN, Sorokovikov VA, Novozilov VA: Management of acute subdural hematomas in infants: intrathecal infusion streptokinase for clot lysis combined with subdural to subgaleal shunt. Childs Nerv Syst 24:437-442, 2008

8. Lin CL, Hwang SL, Su YF, Tsai LC, Kwan AL, Howng SL, et al: External subdural drainage in the treatment of infantile chronic subdural hematoma. J Trauma 57:104-107, 2004

9. Litofsky NS, Raffel C, McComb JG: Management of symptomatic chronic extra-axial fluid collections in pediatric patients. Neurosurgery 31:445-450, 1992

10. Perret GE, Graf CJ: Subgaleal shunt for temporary ventricle decompression and subdural drainage. J Neurosurg 47:590595, 1977

11. Saladino A, Gainsburg D, Zmora E, Ronen Y, Tiberin P: Ventriculosubcutaneous shunt for temporary treatment of neonatal post-IVH hydrocephalus: a technical note. Childs Nerv Syst 2:206-207, 1986

12. Santarius T, Kirkpatrick PJ, Ganesan D, Chia HL, Jalloh I, Smielewski P, et al: Use of drains versus no drains after burr-hole evacuation of chronic subdural haematoma: a randomised controlled trial. Lancet 374:1067-1073, 2009

13. Savitz MH, Malis LI: Subgaleal shunting: a 20 -year experience. Neurosurg Focus 9(6):ECP1, 2000

14. Tolias C, Sgouros S, Walsh AR, Hockley AD: Outcome of surgical treatment for subdural fluid collections in infants. Pediatr Neurosurg 33:194-197, 2000

15. Tubbs RS, Banks JT, Soleau S, Smyth MD, Wellons JC III, Blount JP, et al: Complications of ventriculosubgaleal shunts in infants and children. Childs Nerv Syst 21:48-51, 2005

16. Van Calenbergh F, Bleyen J, Lagae L, Casaer P, Plets C: Long-term external drainage for subdural collections in infants. Childs Nerv Syst 16:429-432, 2000

17. Vinchon M, Noulé N, Soto-Ares G, Dhellemmes P: Subduroperitoneal drainage for subdural hematomas in infants: results in 244 cases. J Neurosurg 95:249-255, 2001

\section{Author Contributions}

Conception and design: Blauwblomme, Puget. Acquisition of data: Blauwblomme. Analysis and interpretation of data: Blauwblomme. Drafting the article: Blauwblomme. Critically revising the article: Puget. Reviewed submitted version of manuscript: Blauwblomme. Approved the final version of the manuscript on behalf of all authors: Blauwblomme. Statistical analysis: Blauwblomme. Study supervision: Di Rocco, Bourgeois, Beccaria, Paternoster, Verchere-Montmayeur, Sainte-Rose, Zerah, Puget.

\section{Correspondence}

Thomas Blauwblomme, Service de Neurochirurgie Pédiatrique, Hôpital Necker Enfants Malades, 149 rue de Sèvres, 75015 Paris, France. email: thomas.blauwblomme@nck.aphp.fr. 